\title{
The Development of Hydrogen Production from
} Lignocellulosic Biomass: Pretreatment and Process

\author{
Wanqian Guo ${ }^{1,}$ a , Ze $\mathrm{He}^{2, \mathrm{~b}}$ and Jing $\mathrm{Li}^{3, \mathrm{c}}$ \\ ${ }^{1,2,3}$ State Key Laboratory of Urban Water Resource and Environment, Harbin Institute of \\ Technology, Harbin 150090, China \\ a guowanqian@126.com, bhiter2015@163.com, c1552955765@qq.com
}

\begin{abstract}
Keywords: Lignocellulosic biomass, hydrogen, bioconversion, pretreatment, fermentation. Abstract. Hydrogen production by conversion of lignocellulosic biomass is both sustainable and environmentally friendly, which has been paid more and more attention all over the world. It is also a great significance to face and alleviate fossil fuels consumption and climate change. The update research advance and technology development of bio-hydrogen production are reviewed, majorly focusing on pretreatment methods, hydrogen-producing microorganisms and process engineering. Meanwhile, a development direction for more efficient and economic bio-hydrogen production is proposed.
\end{abstract}

\section{Introduction}

The development of society and the survival of human beings need a large amount of energy. Nowadays, the most of energy that we consume every day is converted from fossil fuels. However, the reserves of fossil fuels are certainly finite and decreasing [1], while energy requirements are increasing with the population growth [2]. Meanwhile, the $\mathrm{CO}_{2}$ emissions accompanied with the climate change have aroused the extensive concern of environment [3]. Faced with such a serious energy matter, a clean and renewable energy source has become an urgent task [4,5]. Hydrogen is regarded as a good energy carrier for the future [6]. And the biomass-based hydrogen production routes by bioconversion fermentation process has attracted widespread attention $[7,8]$. According to the present relevant studies, the bio-hydrogen production fermentation processes can be classified into photosynthetic fermentation process and anaerobic dark fermentation process $[9,10]$. Compared these two processes, anaerobic fermentation is more advantageous because of its easier operation and control system, lower energy consumption, higher hydrogen production rate, and broader substrates, such as abundant and renewable biomass wastes [11,12].

The cornstalk, which is produced in the agricultural production activity, is an abundant biomass in the world, but most of which can't be used efficiently. For example, China produces about 200 million tons of cornstalks per year, but a large part of which are burned in farmland locally resulting in serious environment pollution $[13,14]$. The cornstalk contains rich lignocellulose, which can been used as the fermentation substrate for the hydrogen production $[15,16]$. As a result, hydrogen production from these agricultural wastes is a resource utilization of transforming "waste" into "treasure". However, the chemical recalcitrance of lignin gives lignocellulosic biomass a nature barrier [17], restricting the direct degradation and utilization of biomass. Therefore, in order to realize the conversion of lignocellulose biomass into hydrogen, lignin should be decomposed by pretreatment processes at first (such as acid hydrolysis, and alkali $[18,19]$ ), then fermented by organisms which can directly utilize cellulose to produce hydrogen.

In this article, the key technology matters about bio-hydrogen production are reviewed, majorly focusing on pretreatment methods, hydrogen-producing microorganisms and process engineering. Meanwhile, a development direction for more efficient and economic bio-hydrogen production is proposed.

\section{Methods of pretreatment}

Pretreatment breaks the barrier of lignin for lignocellulosic material and changes the size, structure and chemical composition of substrates [20]. Furthermore, it hydrolyses some of the hemicellulose, 
decreases cellulose crystallinity and increases cellulose surface area [21]. Hydrolysis should attach tol the following requirements: (i) increase sugar yield, (ii) avoid degradation or loss of sugars, (iii) minimize the formation of inhibitory by-products, (iv) be cost-effective, and (v) recover lignin that can be further converted to co-products (for reviews, see Refs. [22,23]). The selection of pretreatment or hydrolysis methods should be based on the type of the raw substrates and the fermentation conditions.

Pretreatment processes usually contain physical methods (crushing and crushing), chemical methods (acid or ionic solutions), physical chemistry (steam) or biological methods(anaerobic fungi) and other methods. The pretreated substrate can be further hydrolyzed through chemical methods (acid, alkali, ionic solution) or biological methods (biological enzymes, fungi or bacteria, and so on).

Mechanical method. It is generally used in the lignin cellulose material, such as straw, bagasse, corn straw or wheat straw and so on [24]. However, the cost of this method is high and it can not be applied in large scale. Agbor [25] and others believe that this pretreatment method should be limited to use before hydrolysis, although it is likely to be used in the process of lignin cellulose like substances (such as straw).

Physical chemistry method. Thermal hydrolysis and steam explosion pretreatment are energy intensive pretreatment methods, which may not be economically feasible. In addition, these two methods will produce toxic substances, such as furfural, phenolic aldehyde and furfural (HMF) [26], these substances will inhibit subsequent hydrogen production and fermentation [27].

Chemical method. Chemical method can be used for pretreatment and hydrolysis process, dilute acid can obtain high sugar concentration. However, it will produce inhibitory substances. Meanwhile, the residual acid will inhibit hydrogen fermentation. And the application of concentrated acid is not feasible, due to the inhibitors, acid recovery and the neutralization of the hydrolyses. Alkali treatment also produces inhibitors. Overall, higher hydrogen yield is obtained by acid treatment than the alkali treatment [28].

Biological method. The biological pretreatment method mainly uses the fungus which can degrade lignin, to remove package of lignin to the cellulose to facilitate the hydrolysis process [51]. The advantages of biological pretreatment are the proper operating conditions and energy requirements. However, the biological process is complex, which requires the simultaneous optimization of hydrolysis and hydrogen fermentation.

\section{Bio-hydrogen fermentation from Lignocellulosic Biomass}

Hydrogen production process from lignocellulosic biomass generally need to follow the following principles; (1) reducing energy demand; (2) simplifying process; (3) higr hydrogen production rate; (4) cheap raw materials, and ideal utilization efficiency. With the investigation of clear energy production by bioconversion of cellulosic biomass, the cellulose bioconversion process was proposed by scholars, including separate hydrolysis and fermentation (SHF), simultaneous saccharification fermentation (SSF) and consolidated bioprocessing (CBP).

Separate hydrolysis and fermentation (SHF). Hydrolysis and hydrogen production is carried out in the respective reactor without any interference, and the operating conditions are optimized. But reducing sugar produced by the hydrolysis process can't be used immediately. The sugar accumulation would lead to the feedback inhibition, resulting in the decrease of substrates utilization efficiency. Two processes run separately, is bound to increase the difficulty of management difficulty and economic investment would been increased due to separate operation.

Zhao Lei[30]et al. studied the effect of pretreated corn stalk by white rot fungus Chrysosporium Phanerochaete on enzymatic hydrolysis and hydrogen producing bacteria thermosaccharolyticum W16. After 19 days treatment with white rot fungi at $29 \mathrm{C}$, the lignin removal rate was increased to $36 \%$, and the loss of hemicellulose was lower than $10 \%$. The pretreated of straw was hydrolyzed with crude enzyme produced by with viride Trichoderma, the maximum enzymatic hydrolysis rate was $47.3 \%$, which was higher than the $20.3 \%$ of untreated straw. The final saccharification liquid 
was utilized by W16 to produce hydrogen by dark fermentation process, the maximum hydrogen accumulation yield was $80.3 \mathrm{ml} / \mathrm{g}$ - pretreated of corn stalk.

Simultaneous saccharification fermentation (SSF). Hydrogen production and enzymatic hydrolysis process was carried out in the same system and reactor. The produced sugar can be quickly used by the hydrogen producing bacteria, and the negative feedback inhibition of the sugar accumulation to the saccharification process will be relieved. At the same time, the reactor design is simple, convenient due to the two processes are combined together, which results in the decrease of equipment and operation cost. However, the different conditions of two stages, including the temperature, cycle, $\mathrm{pH}$ and other conditions, will make the two reactions difficult to operate at the same time. As a result, the hydrogen yield decreases.

He Yanling[31] et al. studied the hydrogen production in a co-culture way with strains Clostridium thermocellum DSM1237 (cellulose degradation bacteria) and Thermopalmarium Clostridium DSM5974 (can't decompose cellulose). Under the optimal hydrogen production conditions, the filter paper substrate concentration is $9.0 \mathrm{~g} / \mathrm{L}$, the amount of $\mathrm{KHCO}_{3}$ is $40 \mathrm{Mm}$, the maximum hydrogen yield was up to $1387 \mathrm{~mL} / \mathrm{L}$-medium. Lin [32] et al. used the saccharification product of $\alpha$-cellulose to produce bio-hydrogen and ethanol in the batch fermentation way with mixed bacteria group, which was enriched from cow dung. The maximum hydrogen yield and ethanol yield were $2.8 \mathrm{H}_{2} / \mathrm{g}$ - mmol fiber, 5.8 ethanol/g- mmol cellulose, respectively, were obtained under the optimum initial $\mathrm{pH}$ of 7.6 8.0.

Consolidated bio-processing (CBP). The CBP process refers to the production of cellulase, glycosylation and fermentation is concentrated in a system, with a hydrogen producing bacteria or bacteria group to complete the process of direct conversion of cellulose into hydrogen. This process also requires pretreatment to remove the lignin from the cellulose and hemicellulose. Compared with the above two methods, the process does not require a separate enzymatic saccharification reaction, but a separate microorganism directly after the pretreatment of all hydrogen production. In this way, the hydrogen production cost is greatly reduced, and the operation is simple and convenient, and has great industrial potential.

Cao et al. [33] enriched anaerobic mixed microbe as the bacteria source from decaying roots to produce hydrogen, with the pretreated wheat straw by ammonia fiber explosion method. In the optimal pretreatment condition of temperature $100^{\circ} \mathrm{C}$, ammonia: biomass for $1: 1(\mathrm{w} / \mathrm{w})$, processing time $30 \mathrm{~min}$. When the substrate concentration was $0.8 \%$, the maximum hydrogen yield was $16.0 \mathrm{mmol} / \mathrm{L}$, which was $67.8 \%$ higher than that of the untreated straw. Th e study also found that when the substrate is $0.5 \%$, hydrogen production in CBP, SSF, SHF were $16.2,8.0,18.3 \mathrm{mmol} / \mathrm{L}$, respectively. When the substrate concentration was $1.0 \%$, hydrogen yield were 16.2, 8.2, $32.5 \mathrm{mmol} / \mathrm{L}$, respectively. That showed that the CBP method provides a more promising and economically hydrogen production process compared with SSF and SHF process.

\section{Conclusions}

The hydrogen production by conversion of lignocellulosic biomass is still in the initial stage, there are still some technical problems need to been explored and resolved. The main research and development direction of lignocellulosic biomass conversion are as follows:

(1) Investigate the effective and economical pretreatment method; optimize the pretreatment process according to the different biomass and decrease the inhibition matters produced in pretreatment.

(2) Establish the directional hydrogen bioconversion technology of lignocellulosic biomass; developing of a variety of microbial cells immobilized methods to promote the tolerance stress of organisms; enhancing microbial biomass, decrease the inhibition component hydrolysate; and improve the stability of hydrogen production system.

(3) Explore advanced bio-hydrogen production process to enhance the hydrogen yield, promote the substrates utilization efficiency, decrease the production cost; realize the large-scale industrial hydrogen production by bio-conversion of lignocellulosic biomass. 


\section{Acknowledgements}

This work was financially supported by National science and technology plan of China (2014BAD02B03), and Fund for young top-notch talent teachers by Harbin Institute of Technology (AUGA5710052514). The authors also gratefully acknowledge the financial support by State Key Laboratory of Urban Water Resource and Environment (2015TS06).

\section{References}

[1] Saxena RC, Adhikari DK, Goyal HB. Biomass-based energy fuel through biochemical routes: a review. Renew Sustain Energy Rev 2009;13(1):167-78.

[2] IEA. World energy outlook 2010. Paris: International Energy Agency; $2010 .$.

[3] Environmental Protection Agency. Standards of performance for greenhouse gas emissions from new, modified, and reconstructed stationary sources: electric utility generating units. Fed Regist 2015;80:64510-660. no. 205/Friday.

[4] Regulation (EU) No 333/2014 of the European Parliament and of the Council of 11 March 2014 Amending Regulation (EC) No 443/2009 to define the modalities for reaching the 2020 target to reduce CO2 emissions from new passenger cars. Off J Eur Union L103 2014;57:15-22

[5] Merkisz J, Pielecha J, Radzimirski S. In: Roess RP, editor. New trends in emission control in the European Union, vol. 4. , Heidelberg: Springer; 2014.

[6] Dodds PE, Staffell I, Hawkes AD, Li F, Gru“ newald P, McDowall W, et al. Hydrogen and fuel cell technologies for heating: a review. Int J Hydrogen Energy 2015;40:2065e83

[7] Luo G, Xie L, Zou ZH, Wang W, Zhou Q, Shim H. Anaerobic treatment of cassava stillage for hydrogen and methane production in continuously stirred tank reactor (CSTR) under high organic loading rate (OLR). Int J Hydrogen Energy 2010;35:11733e7.

[8] Hoogwijk M, Faaij A, van den Broek R, Berndes G, Gielen D, Turkenburg W. Exploration of the ranges of the global potential of biomass for energy. Biomass Bioenergy 2003;25(2):119-23.

[9] Yuan XZ, Shi XS, Zhang PD, Wei YL, Guo RB, Wang LS. Anaerobic biohydrogen production from wheat stalk by mixed microflora: kinetic model and particle size influence. Bioresour Technol 2011;102:9007-12.

[10]Zhao L, Cao GL, Yao J, Ren HY,MaF, Ren NQ, et al. Optimization of immobilization parameters of Thermoanaerobacterium thermosaccharolyticum W16 on a new carrier for enhanced hydrogen production. RSC Adv 2012;2:7391-5.

[11]Ren NQ, Wang AJ, Cao GL, Xu JF, Gao LF. Bioconversion of lignocellulosic biomass to hydrogen: potential and challenges. Biotechnol Adv 2009;27:051-60.

[12]Lo YC, Bai M, Chen W, Chang J. Cellulosic hydrogen production with a sequencing bacterial hydrolysis and dark fermentation strategy. Bioresour Technol 2008;99:8299-303

[13]Chaganti SR, Pendyala B, Lalman JA, Veeravalli SS, Heath DD. Influence of linoleic acid, $\mathrm{pH}$ and HRT on anaerobic microbial populations and metabolic shifts in ASBRs during dark hydrogen fermentation of lignocellulosic sugars. Int J Hydrogen Energy 2013;38:2212e20.

[14]Nkemka VN, Murto M. Biogas production from wheat straw in batch and UASB reactors: the roles of pretreatment and seaweed hydrolysate as a co-substrate. Bioresour Technol 2013;128:164-72. 
[15]Lei Zhao, Guang Li Cao Ai-Jie Wang, Hong-Yu Ren, Nan-Qi Ren. Evaluation of continuous biohydrogen production from enzymatically treated cornstalk hydrolysate. Hydrogen Energy 2013; 38: 15100-15104.

[16]Simultaneous saccharification and fermentation of fungal pretreated cornstalk for hydrogen production using Thermoanaerobacterium thermosaccharolyticum W16. Bioresource Technology 2013; 45:103-107.

[17] Nitsos CK, Matis KA, Triantafyllidis KS. Optimization of hydrothermal pretreatment of lignocellulosic biomass in the bioethanol production process. ChemSusChem 2013;6:110e22.

[18]Pattra S, Sangyoka S, Boonmee M, Reungsang A. Biohydrogen production from the fermentation of sugarcane bagasse hydrolysate by Clostridium butyricum. Int $\mathrm{J}$ Hydrogen Energy 2008;33:5256-65.

[19]Fangkum A, Reungsang A. Biohydrogen production from sugarcane bagasse hydrolysate by elephant dung: effects of initial $\mathrm{pH}$ and substrate concentration. Int $\mathrm{J}$ Hydrogen Energy 2011;36(14):8687-96

[20] Mosier N, Wyman C, Dale B, Elander R, Lee YY, Holtzapple M, et al. Features of promising technologies for pretreatment of lignocellulosic biomass. Bioresour Technol 2005;96(6):673-86.

[21]Ren N, Wang A, Cao G, Xu J, Gao L. Bioconversion of lignocellulosic biomass to hydrogen: potential and challenges. Biotechnol Adv 2009;27(6):1051-60.

[22] Brodeur G, Yau E, Badal K, Collier J, Ramachandran KB, Ramakrishnan S. Chemical and physicochemical pretreatment of lignocellulosic biomass: a review. Enzyme Res 2011;2011:787532.

[23] Chandra R, Bura R, Mabee W, Berlin A, Pan X, Saddler J. Substrate pretreatment: the key to effective enzymatic hydrolysis of lignocellulosics? Adv Biochem Eng Biotechnol 2007;108:67-93.

[24] Cakir A, Ozmichi S, Kargi F. Comparison of bio-hydrogen production from hydrolyzed wheat starch by mesophilic and thermophilic dark fermentation. Int J Hydrogen Energy 2010;35(24):13214-8.

[25] Agbor VB, Cicek N, Sparling R, Berlin A, Levin DB. Biomass pretreatment: fundamentals toward application. Biotechnol Adv 2011;29(6):675-85.

[26] Jung KW, Kim DH, Shin HS. Fermentative hydrogen production from Laminaria japonica and optimization of thermal pretreatment conditions. Bioresour Technol 2011;102(3):2745-50.

[28]Cao GL, Ren NQ, Wang AJ, Guo WQ, Xu JF, Liu BF. Effect of lignocellulose-derived inhibitors on growth and hydrogen production by Thermoanaerobacterium thermosaccharolyticum W16. Int J Hydrogen Energy ２010;35(24):13475-80

[29] Pan C, Zhang S, Fan Y, Hou H. Bioconversion of corncob to hydrogen using anaerobic mixed microflora. Int J Hydrogen Energy 2010;35(7):2663-9.

[30]Lei Zhao, Guangli Cao, Aijie Wang et al.Fungal pretreatment of cornstalk with Phanerochaete chrysosporium for enhancing enzymatic saccharification and hydrogen production. Bioresource Technology.2012,114(2012):365-369 
[31] Geng A, He YL, Qian CL, et al. Effect of key factors on hydrogen production from cellulose in a co-culture of Clostridium thermocellum and Clostridium thermopalmarium. Bioresour Technol, 2010, 101: 4029-4033

[32] Lin CY, Hung WC. Enhancement of fermentative hydrogen/ethanol production from cellulose using mixed anaerobic cultures. Int J Hydrogen Energ, 2008, 33: 3660-3667.

[33] Guang-Li Cao , Xun-Feng Xia , Lei Zhao,et al. Development of AFEX-based consolidated bioprocessing on wheat straw for biohydrogen production using anaerobic microflora.Hydrogen Energy.2013,38(2013):15653 15659 